\title{
DIVERSIDADE CULTURAL BRASILEIRA ADVINDA DO PROCESSO DE COLONIZAÇÃO
}

\author{
Jeová Pereira de Jesus ${ }^{1}$ \\ Gilberto Rineldi da Silva ${ }^{2}$
}

RESUMO: Este artigo, através de pesquisa bibliográfica, aborda a diversidade cultural presente no Brasil. Essa pluralidade de culturas é reflexo do processo de colonização que se iniciou no ano de 1530 e foi designado na história do Brasil como período colonial. Os diversos povos que vieram de outros continentes explorar as riquezas brasileiras e também os que foram trazidos como escravos ajudaram a construir a identidade cultural existente no país. Identidade essa caracterizada por um misto de culturas provenientes de várias partes do mundo acrescidas da cultura dos índios nativos que já habitavam a região. Nos dias atuais ainda é possível observar dentro do território brasileiro manifestações culturais distintas entre as cinco regiões que deixam evidente o responsável pela colonização do local. Além disso, são realizadas discussões sobre preconceitos e divisão de classes sociais oriundas do papel adotado na sociedade pelo colonizador e colonizado deixando evidente o processo de colonização que existiu no país.

Palavras-chave: Diversidade Cultural. História do Brasil. Colonização. Período Colonial.

\section{INTRODUÇÃO}

$\mathrm{Na}$ história do Brasil o período colonial é compreendido entre os anos de 1530 a 1822, porém antes dessa data no dia 22 de abril de 1500 chega no território brasileiro a esquadra de Pedro Álvares Cabral composta por io naus e 3 caravelas chefiadas pelos navegadores Bartolomeu Dias, Nicolau Coelho e Duarte Pacheco Pereira. Os anos de I50o a 1530 ficaram conhecidos como período pré-colonial e foi nesse intervalo de tempo que

\footnotetext{
I Especialista em Docência no Ensino Superior, Auditoria e Controladoria Financeira: Faculdade única FUNIP. Graduação em História, Pedagogia pelo Centro Universitário internacional - UNINTER.

2 Pós-Graduação em Metodologia do Ensino de Matemática (2021 - em curso); Pós-Graduação em Metodologia do Ensino de História (2021 - em curso); Pós-Graduação em Educação e Novas Tecnologias (2021); Pós-Graduação em Formação Docente para EAD (2019); Licenciado em Matemática (2018); Licenciado em Pedagogia (2020); Licenciado em História (2020) pelo Centro Universitário Internacional UNINTER; Participa do grupo de pesquisa intitulado "A formação docente e as práticas de Estágio e Conclusão de Curso"; Participou do grupo Eureka como professor de Matemática; Trabalhou na Escola Superior de Educação no setor NAPPP - Núcleo de Apoio e Pesquisa e Pratica Pedagógica no cargo de Assistente de Operações Acadêmicas; Atualmente é docente no Ensinos Fundamental, Médio e Técnico na disciplina de Matemática pela Secretaria Estadual de Educação do Estado do Paraná - SEED/PR e professor avaliador de trabalhos acadêmicos no Centro Universitário Internacional UNINTER.
} 
descobriram o pau-brasil, uma madeira nativa da Mata Atlântica, que fazia sucesso no mercado consumidor europeu e também deu origem ao nome Brasil.

A colonização brasileira foi inicialmente feita pelos portugueses que ameaçados por outras potências marítimas tiveram que assegurar o domínio da terra. Foi então implantado pela coroa o modelo de capitanias hereditárias dividindo-as em is capitanias para 12 donatários sendo que alguns receberam mais que uma porção de terra e as Capitanias do Maranhão e São Vicente foram divididas em duas porções. Os donatários eram possuidores, mas não proprietários da terra, ou seja, não podiam vender ou dividir a capitania.

A criação das capitanias hereditárias não foi suficiente para o monopólio português. A colônia do Brasil passou a despertar interesse em outros povos que assombravam o governo lusitano por meio da ação de piratas e corsários ingleses, invasores franceses e invasores holandeses que disputavam o domínio do litoral brasileiro.

De acordo com Boris Fausto:

A Coroa lusa abriu brechas nesses princípios, principalmente devido aos limites de sua capacidade de impô-los. Não estamos falando apenas da existência do contrabando, pois o contrabando era uma quebra pura e simples das regras do jogo. Estamos falando sobretudo da posição de Portugal no conjunto das nações europeias. Os portugueses estiveram na vanguarda da expansão marítima, mas não tinham os meios de monopolizar seu comércio colonial. Já durante o século $\mathrm{XVI}$, as grandes praças comerciais não se situavam em Portugal, mas na Holanda. Os holandeses foram importantes parceiros comerciais de Portugal, transportando sal e vinho portugueses e açúcar brasileiro, em troca de produtos manufaturados, queijos, cobre e tecidos. Obtiveram com isso muitas facilidades". (Fausto, 1996, p. 32).

Economicamente, esse movimento deu origem aos três pilares econômicos que seguiram pelo país durante mais de três séculos: a monocultura (produção da cana de açúcar), ao latifúndio (grandes propriedades de terra concentradas nas mãos dos senhores) e a mão-de-obra escrava. A mão-de-obra dos índios que já habitavam no território por sua vez se mostrou ineficiente para atender ao estilo de trabalho imposto pelos colonizadores sendo assim necessário exportar mão-de-obra de outros países. Acerca desse assusto Caio Prado Júnior ressaltou:

Além da resistência que ofereceu ao trabalho, o índio se mostrou mau trabalhador, de pouca resistência física e eficiência mínima. Nunca teria sido capaz de dar conta de uma tarefa colonizadora de larga escala. Está aí o exemplo 
da Amazônia, onde não chegou a ser substituído em escala apreciável por outro trabalhador e onde, em grande parte por isso, a colonização estagnou até quase nossos dias. É que de um lado, o índio brasileiro, saindo de uma cultura tão primitiva, não podia adaptar-se com a necessária rapidez ao sistema e padrões de uma cultura tão superior quanto aquela que lhe traziam os brancos." (PRADO JR., 2000, p. 35).

No período de colonização não existia uma ideia de unidade da nação brasileira e cada morador possuía uma identidade cultural baseada na sua localidade de origem. Foi a partir daí que deu início ao processo desorganizado e violento de miscigenação brasileira, entre europeus, africanos e indígenas. Essa interação mesmo que não intencional entre os povos gerou uma junção de elementos de todas as culturas que ainda estão presentes na cultura do século XXI. A exclusão social de descendentes dos povos que eram escravizados no período colonial por exemplo ainda é assunto que gera discussões e controvérsias em todo país.

A principal linha de desenvolvimento do trabalho será de destacar as influências culturais deixadas pelos colonizadores e colonizados no país especificando em qual segmento cada povo se destacou mais. O tema pesquisado decorre de questionamentos feitos pelo autor ao longo de sua vida e também durante seu período de formação acadêmica sobre a origem da cultura diversificada existente no Brasil.

A misticidade de culturas presentes entre os brasileiros e também discussões sobre problemas sociais despertaram o interesse do autor pelo ingresso no curso de licenciatura em história.

\section{DESENVOLVIMENTO}

\section{I Herança histórico-cultural}

Netto, Dias e Mello (2003) pontua que aspectos importantes da cultura da organização emanam de traços da cultura nacional e, neste sentido, traços singulares dessa cultura precisam ser delineados antes da aplicação de metodologias para análise de traços da cultura organizacional. Tais traços refletem os pressupostos que mesmo arraigados no inconsciente são utilizados por cada indivíduo para enxergar a si mesmo e têm origem histórica, econômica e antropológica.

Ainda segundo os autores: 
A formação desses traços tem íntima relação com os fatores de formação do país: sua colonização, a cultura específica que o colonizou e formas de poder que atuaram no processo de sua formação, consolidação e desenvolvimento." (NETTO; DIAS; MELLO,2003, p.2).

A identidade cultural de uma nação está intimamente ligada à sua história. Acerca desse tema Rita afirmou:

Se todas as nações são diferentes e singulares, o que marca essa diferença? Como se distinguem, sendo vizinhas, partilhando paisagens, etnias, línguas e actividades? As nações distinguem-se pela sua auto definição histórica, que, longe de ser uma emanação das origens, é antes o produto voluntarista de um percurso temporal fixado em sucessivas representações do querer-ser. Em termos mais simples, o que sustenta a distinção entre nações é a identidade nacional, essa quintessência que pretende condensar um território e o povo que o habita e ligálos umbilicalmente aos tempos imemoriais da origem." (RIBEIRO,2008, p.I3).

Antônio Gramsci em "Concepção Dialética da História", disserta a respeito da importância da busca pelo conhecimento do movimento formador das relações sociais:

Estas relações, contudo, como vimos, não são simples. Enquanto algumas delas são necessárias, outras são voluntárias. Além disso, ter consciência mais ou menos profunda delas (isto é, conhecer mais ou menos o modo pelo o qual elas podem se modificar) já as modifica. As próprias relações necessárias, na medida em que são conhecidas em sua necessidade, mudam de aspecto e de importância. Neste sentido, o conhecimento é poder. Mas o problema é complexo, ainda por outro aspecto: não é suficiente conhecer o conjunto das relações enquanto existem em um dado momento como um dado sistema, mas importa conhecê-los geneticamente, em seu movimento de formação, já que todo indivíduo é não somente a síntese das relações existentes, mas também da história destas relações, isto é, o resumo de todo o passado." (GRAMSCI, I995, p. 40).

Para o autor não é suficiente analisar as relações sociais baseando-se apenas em um período. É necessário a busca pelo conhecimento da história de um povo para que seja feita uma análise concreta das relações sociais existentes.

Sousa em seu trabalho acadêmico" re-visitando a história: colonização portuguesa e subordinação cultural" destacou o somatório de confrontos culturais entre os diversos povos no Brasil colônia:

O Brasil, durante a sua formação colonial, esteve submetido a uma somatória de confrontos entre as mais diversas identidades que, num jogo de amalgamentos culturais, resultou, desde os primeiros séculos de ocupação e exploração, em verdadeiras ilhas socioculturais, cujo formato dissonante parece permanecer até os dias atuais." (SOUSA, 2008, p.3).

No Brasil colônia, os primeiros colonizadores portugueses trouxeram consigo a cultura de Portugal e comportavam-se em conformidade com ela visando o 
enriquecimento repentino e a forma de viver com todas regalias da nobreza. Apesar dos fortes laços com a posse e cultivo da terra, os lusitanos não eram acostumados em trabalhar diretamente as terras e lavouras. Os colonos eram culturalmente moldados a serem senhores e usufruir dos lucros da atividade agrícola.

A cultura brasileira sofreu influência ao longo de sua história por diversos povos. O pioneiro da colonização e que mais influenciou foi Portugal que exportou mão-de-obra da África para trabalhar as terras descobertas. Além de mão-de-obra estrangeira, os índios nativos que até os anos de 1500 habitavam e exploravam as riquezas naturais para sobrevivência se tornaram escravos. Os franceses e holandeses também vieram para o país e deixaram suas marcas na identidade cultural do Brasil.

Acerca da imposição cultural ditada pelos europeus na colônia brasileira Sousa também afirmou:

No Brasil, a sobreposição cultural dos conquistadores europeus junto aos povos africanos - em seu doloroso processo diaspórico -, somados ainda a dos povos sulamericanos - que também na sua enorme diversidade contribuíram para a formatação de uma "nova nação" -, não implicou em torná-la necessariamente homogênea. Ao contrário, os preceitos hierarquizantes de assimilação cultural imposta pela força da aculturação, respaldados na miscigenação e no aniquilamento desses povos tidos como "inferiores", agora estão sendo substituídos pelos preceitos de integração, onde procedem a preservação identitária e reivindicatória dos grupos étnicos submetidos a constantes confrontações em sua dinâmica cultural." (SOUSA, 2008, p.3).

O que fez os europeus cruzarem o Oceano Atlântico e chegarem a uma "ilha distante" não foi a propagação de costumes ou imposição cultural. As influências culturais deixadas por esses povos em suas colônias é a consequência do processo de colonização que automaticamente fez com que os colonizadores buscassem outros povos vistos como um ser socialmente inferior para trabalharem nas suas terras.

\section{I.I Influência Portuguesa}

Portugal foi o país europeu que mais influenciou as tradições, costumes e símbolos do Brasil. Devido ao longo período que o país foi colonizado pelos portugueses a transplantação de pessoas e da cultura típica da metrópole para as terras sul-americanas foi inevitável. 
Durante o processo de colonização do Brasil os portugueses tiveram que se relacionar com os índios nativos, que já habitavam a região e com os africanos trazidos posteriormente para trabalhar nas lavouras de cana-de-açúcar e também na produção do engenho. $O$ relacionamento com esses povos que carregavam consigo sua própria identidade cultural provocou mutações na cultura dos primeiros colonizadores. Inevitáveis mudanças foram sendo desenhadas e em alguns colonos causou deformações já em outros aperfeiçoamentos.

Para Silva (2006) as transformações culturais não surgiram instantaneamente, foi necessário transcorrer um período de modificações sociais para que pudessem ser observadas. Ainda que existissem algumas alterações na cultura do Brasil colônia, o modo de ser dos colonizadores era hegemonicamente fundamentado na cultura portuguesa.

Em um contexto nacional, os procedimentos de colonização portuguesa proporcionaram a formação de domínios coloniais que, ao serem presididos pela lógica mercantilista e também religiosa, acabou determinando a subordinação sociocultural, econômica e política dessas "novas terras", dentre outras adversidades que foram e continuam sendo mantidas até os dias atuais." (SOUSA, 2008, p.2).

O principal objetivo dos lusitanos na colonização do Brasil não era difundir a cultura de Portugal. O objetivo deles era a exploração do território de modo que o mercado português fosse expandido. A miscigenação de culturas foi a consequência desse processo. De modo geral, a cultura portuguesa foi a responsável pela introdução no Brasil colônia dos grandes movimentos artísticos europeus: renascimento, maneirismo, barroco, rococó e neoclassicismo.

Ana Cristina Nogueira da Silva e Antônio Manuel Hespanha em "A Identidade Portuguesa", descreveram características que se configuraram na formação da identidade cultural de Portugal e que foram transmitidas as suas colônias:

Já veremos, na verdade, que os portugueses não eram apenas isso; que eram também (e sobretudo) católicos, que eram (muito menos) europeus, que eram hispânicos; que eram, depois, minhotos ou beirões; vassalos do rei ou de um senhor; eclesiásticos, nobres ou plebeus; homens ou mulheres. E que, sendo tudo isto, sem deixarem de ser portugueses, eram portugueses de uma maneira muito menos nítida e unidimensional do que o hoje supomos, à luz dos paradigmas de distinção nacional (agora, em português) 2 estabelecidos desde o século passado.” (SILVA e HESPANHA, 1993, p. 19). 
A principal herança lusitana para a cultura brasileira foi a língua portuguesa. Atualmente é a língua oficial falada em todo o território nacional e matéria obrigatória de estudo na formação escolar. Já no âmbito religioso os portugueses deixaram de herança o catolicismo e suas tradições como criação do calendário religioso, festas e procissões.

O carnaval, as festas juninas, as cavalhadas, o bumba-meu-boi, o fandango, a crença em seres fantásticos como a cuca, o bicho-papão e o lobisomem além de muitas lendas também denotam grande influência portuguesa. $\mathrm{Na}$ culinária, muitos dos pratos típicos brasileiros resultaram da adaptação de pratos portugueses às condições da colônia.

\subsubsection{Influência Indígena}

Quando os europeus chegaram ao Brasil colônia encontraram a população indígena que já habitavam a região ao longo da costa e na bacia dos Rios Paraná-Paraguai. Os nativos eram dotados de língua, costumes e hábitos diferentes dos colonizadores. Muitas das práticas culturais dos indígenas como canibalismo, incesto e o infanticídio neonatal assustaram os colonos.

O espaço geográfico dos índios brasileiros estava dividido em tribos, de acordo com o tronco linguístico ao qual pertenciam: tupi-guaranis (região do litoral), macro-jê ou tapuias (região do Planalto Central), aruaques ou aruak (Amazônia) e caraíbas ou karib (Amazônia). Os portugueses posteriormente identificaram outros povos indígenas, como os carijós, os tupiniquins, os tamoios etc.

Os colonizadores que chegaram a região não eram acostumados com o trabalho árduo das lavouras e engenho, o que objetivavam era somente viver do lucro dessas atividades. Os nativos de imediato foram utilizados pelos colonos como mão-de-obra escrava para cultivar as terras. A distinção de culturas entre colonizador e colonizado eram evidentes e causaram estranheza em ambas as partes.

O contato dos índios com os colonizadores provocou nos nativos um misto de sentimentos. Os portugueses eram ao mesmo tempo respeitados, temidos e odiados e eram vistos como homens dotados de poderes especiais. De acordo com Fausto (1996, p.22) "os índios que se submeteram ou foram submetidos sofreram a violência cultural, as epidemias 
e mortes. Do contato com o europeu resultou uma população mestiça, que mostra, até hoje, sua presença silenciosa na formação da sociedade brasileira."

Os indígenas que habitavam o Brasil antes da colonização portuguesa tinham vários costumes próprios que causaram estranheza nos colonos. Para sobreviver utilizavam-se da caça, pesca e do cultivo da mandioca, milho, amendoim, feijão, abóbora, bata-doce entre outros. A agricultura era praticada de forma bem peculiar e primitiva uma vez que utilizavam a técnica agrícola tradicional chamada de coivara.

Os índios domesticavam animais de pequeno porte como, por exemplo, porco do mato e capivara. Não conheciam o cavalo, o boi e a galinha. As tribos indígenas possuíam uma relação baseada em regras sociais, políticas e religiosas. $O$ contato entre as tribos acontecia somente em momentos de guerras, casamentos, cerimônias de enterro e também no momento de estabelecer alianças contra um inimigo comum.

Os índios faziam seus objetos utilizando-se das matérias-primas extraídas da natureza. $\mathrm{O}$ respeito ao meio-ambiente sempre foi presente na cultura indígena de modo que retiravam somente o necessário para a sobrevivência. Da madeira encontrada na mata nativa construíam canoas, arcos e flechas e suas habitações (oca). A palha era utilizada para fazer cestos, esteiras, redes e outros objetos. A cerâmica era muito utilizada para fazer potes, panelas e utensílios domésticos em geral. Penas e peles de animais serviam para fazer roupas ou enfeites para as cerimônias das tribos. Já o urucum era utilizado para fazer pinturas no corpo.

\subsubsection{Influência Africana}

Os índios através de fuga, brigas, recusa ao trabalho compulsório dentre outros resistiram às várias formas de imposição dos colonizadores. Em termos comparativos, os nativos tinham mais formas de resistência e rebeldia do que os escravos africanos. Enquanto estes se encontravam diante de um território desconhecido onde eram trazidos à força, aqueles estavam em sua terra e conheciam toda a região. No entanto, não se pode afirmar que os africanos aceitaram a escravidão e seus castigos de forma passiva. Existiram vários movimentos de luta da população negra pela liberdade. Sobre o assunto Boris Fausto observou: 
Seria errôneo pensar que, enquanto os índios se opuseram à escravidão, os negros a aceitaram passivamente. Fugas individuais ou em massa, agressões contra senhores, resistência cotidiana fizeram parte das relações entre senhores $e$ escravos, desde os primeiros tempos. Os quilombos, ou seja, estabelecimentos de negros que escapavam à escravidão pela fuga e recompunham no Brasil formas de organização social semelhantes às africanas, existiram às centenas no Brasil colonial. Palmares - uma rede de povoados situada em uma região que hoje corresponde em parte ao Estado de Alagoas, com vários milhares de habitantes foi um desses quilombos e certamente o mais importante. Formado no início do século XVII, resistiu aos ataques de portugueses e holandeses por quase cem anos, vindo a sucumbir, em 1695, às tropas sob o comando do bandeirante Domingos Jorge Velho”. (Fausto, 1996, p. 30).

A cultura africana chegou ao Brasil através dos escravos trazidos da África durante o período do tráfico negreiro transatlântico. Além do choque cultural que ocorreu quando chegaram a colônia, existia também a diversidade entre os próprios africanos. Incluíam na lista dos escravizados bantos, nagôs e jejes os quais pertenciam a etnias distintas e cujas crenças religiosas deram origens a diversas religiões afro-brasileiras. As culturas indígenas e africanas sofreram diversas tentativas de supressão por parte dos colonizadores. $\mathrm{Na}$ colônia, era ensinado aos escravos o português, língua oficial de Portugal, os nomes eram mudados para nomes de origem portuguesa e eram obrigados a seguir as práticas religiosas da coroa, o catolicismo.

Existiram vários argumentos para justificar a escravidão africana no Brasil. Os portugueses pregavam que se tratava de uma instituição já existente na África e que apenas levavam os cativos para o mundo cristão, onde seriam civilizados e salvos pelo conhecimento da verdadeira religião. Nem a igreja que tinha influência na época nem a coroa se opuseram ao tráfico de escravos. Os negros eram vistos como um ser racialmente inferior a qualquer outra raça. Diversas ordens religiosas como a dos beneditinos faziam parte do dia-a-dia da colônia. No decorrer do século XIX, teorias pretensamente científicas fortaleceram o preconceito difundido pelos brancos: o tamanho, a forma do crânio dos negros, o peso do cérebro, entre outras características físicas "demonstravam" que estavam diante de uma raça de baixa inteligência e emocionalmente instável, destinada biologicamente aos trabalhos braçais que não intelectualidade.

A contribuição dos povos africanos com a cultura brasileira é vasta e se estendeu ao longo da história do Brasil. Os costumes da África foram introduzidos e influenciaram o país em diversos segmentos: dança, música, religião, culinária e idioma. A influência 
cultural está presente em várias partes do território brasileiro, em especial nos estados da Bahia, Maranhão, Pernambuco, Alagoas, Minas Gerais, Rio de Janeiro, São Paulo e Rio Grande do Sul onde em virtude da migração dos escravos a cultura afro-brasileira é destacada.

Religiões e rituais que começaram a ser praticados ao longo dos anos tiveram origem no Brasil colonial. Os escravos foram os responsáveis por difundir o candomblé (religião afro-brasileira baseada no culto aos orixás) e a umbanda (religião sincrética que mistura elementos africanos com o catolicismo e o espiritismo incluindo a associação de santos católicos com os orixás).

$\mathrm{Na}$ culinária também os africanos deixaram seus sabores. A Bahia foi o estado que mais absorveu os gostos dos escravos. Diversos pratos típicos como vatapá, o caruru e o acarajé são de origem africana. O azeite-de-dendê extraído de uma palmeira africana é utilizado em vários pratos.

$\mathrm{Na}$ música o povo africano contribuiu com vários ritmos musicais que foram a base para boa parte da música popular brasileira. Gêneros musicais coloniais de influência

africana, como o lundu, deram origem à base rítmica do maxixe, samba, choro, bossa-nova dentre outros gêneros musicais atuais. Também existem alguns instrumentos musicais brasileiros, como o berimbau, o afoxé e o agogô, que são de origem africana. O berimbau é o instrumento utilizado para criar o ritmo que acompanha os passos da capoeira, mistura de dança e arte marcial criada pelos escravos no Brasil colonial.

\subsubsection{Influência Francesa}

A chegada dos franceses no Brasil foi quase simultânea ao descobrimento pelos portugueses. No ano de 1504, o capitão Binot Paulmier de Gonneville e sua esquadra passaram seis meses convivendo com os índios carijós. Ao partirem do país levaram consigo um dos índios que se manteve por toda a vida na França.

Em 1555 foi fundada na Baía da Guanabara a colônia França Antártica de Nicolas Durand de Villegaignon que tinha como objetivo a construção de uma base naval e militar para fortalecer o comércio com os nativos e atacar navios ibéricos. Já em 1612 foi criada uma nova colônia e dessa vez a região escolhida foi o atual estado do Maranhão. Em I743 
Charles-Marie de la Condamine liderou uma expedição científica que descobriu a borracha na Amazônia.

Os portugueses no ano de 1560 expulsaram Nicolas Durant de Villegagnon da Baía da Guanabara, porém, mesmo após a derrota, os franceses continuaram por muitos anos e em períodos diferentes na história do Brasil exercendo influência na região. Os lusitanos após a derrota da França criaram a cidade de São Sebastião no Rio de Janeiro como forma de mostrar seu domínio sobre a região.

Mesmo não tendo sido a principal potência colonizadora do Brasil nem ter tido o domínio econômico como ocorreu com Portugal, a França foi responsável por difundir sua cultura e influenciar comportamentos da elite determinando modelos de vida social e referências intelectuais, desde a filosofia até a moda, da gastronomia à literatura. Os franceses também contribuíram para a renovação das artes e causaram mudanças de hábitos culturais e sociais, ajudando na construção da identidade brasileira.

Apesar do principal objetivo da França em colonizar o Brasil fosse explorar as riquezas da região a imposição cultural dos franceses foi inevitável. "Não eram apenas

produtos industrializados que começavam a ser importados, mas também ideias, hábitos e costumes. As elites brasileiras passaram a demonstrar o desejo de constituírem uma cultura cosmopolita, correspondente ao que acontecia na Europa. A própria elite portuguesa manifestava a vontade de "europeizar-se", e com a queda de Napoleão, os laços culturais entre França e Portugal foram retomados.” (PETER, 2007).

\subsubsection{Influência Holandesa}

As invasões holandesas no Brasil ocorreram no século XVII (anos de r630 a I654) quando os holandeses ocuparam territórios no Nordeste brasileiro. A tomada das regiões estava diretamente relacionada com os emblemas políticos que envolviam Portugal, Espanha e Holanda naquela época. Os holandeses buscavam construir sua própria colônia na América do Sul ao se apropriarem de uma das principais praças produtoras de açúcar sob o domínio português.

Até 1580, a Holanda teve um envolvimento direto com o negócio do açúcar produzido no Brasil, pois foram os responsáveis por financiar o desenvolvimento da 
atividade aqui no país e também participar do refino e comércio do produto pela Europa. A atividade açucareira rendeu satisfatório lucro para Portugal e Holanda. Entretanto, essa situação sofreu profundas modificações com a crise da dinastia de Avis em Portugal, no final do século XVI. A crise de sucessão deflagrou-se quando Dom Henrique, cardeal rei de Portugal, morreu e não deixou herdeiros legítimos.

Após a morte do rei sem deixar herdeiros foi instaurada uma crise de sucessão que resultou na coroação do rei Filipe II da Espanha, como rei de Portugal. A unificação das duas potências sob o domínio do mesmo rei foi inevitável e ficou conhecido como União Ibérica. Naturalmente, mudanças drásticas aconteceram nas relações diplomáticas entre os dois países nesse período.

Os holandeses até o ano de 158r estavam sob o domínio dos Habsburgo, dinastia que reinava na Espanha, e lutavam pela independência do país. Existia uma guerra consolidada entre Espanha e Holanda. A partir do momento em que Portugal e Espanha passaram a defender os interesses da mesma coroa, os inimigos da Espanha também se tornaram inimigos de Portugal.

Dessa forma, os holandeses acabaram sendo excluídos do negócio do açúcar o que resultou em uma série de contra-ataques por parte deles em territórios dominados por Portugal. Portos portugueses no continente africano foram saqueados em 1595 e em 1604 atacaram a cidade de Salvador, na Bahia. As ações holandesas contra a coroa portuguesa acabaram fracassando. Após os ataques a Portugal, Espanha e Holanda permaneceram em trégua até I62I o que consequentemente acarretou na trégua entre Portugal e Holanda.

No ano de 1621 foi fundada a WIC (West-Indische Compagnie) ou Companhia Holandesa das Índias Ocidentais que tinha como principal objetivo tirar o domínio de Portugal sobre os locais produtores de açúcar, bem como assumir o controle dos postos de comércios de escravos na África. Em 1624 os holandeses conquistaram após 24 horas de batalha a capital do Brasil da época, a cidade de Salvador. O controle dos holandeses ficou concentrado somente na cidade, uma vez que os colonos e os portugueses resistiram e não permitiram que os holandeses ampliassem o domínio pelo Recôncavo Baiano. 
Após um ano de invasão, Portugal conseguiu expulsar os holandeses em grande parte devido a chegada de aproximadamente 12 mil homens. Porém, em 1627 os holandeses retornaram à cidade de Salvador para saquear e também foram expulsos.

Depois do fracasso na cidade de Salvador, os holandeses invadiram outro estado brasileira, Pernambuco, que prosperava com a produção de açúcar. Em i630, uma expedição holandesa formada por 65 embarcações e 7280 homens atacou a cidade de Olinda. Até os anos de 1637 conseguiram estender o domínio para outras regiões do Nordeste tais como Paraíba e o Rio Grande do Norte.

Em 1637, chega em Recife, enviado pela WIC, Maurício de Nassau para administrar os domínios da colônia holandesa. Ele era um militar e foi indicado para assumir o cargo e aqui permaneceu até I643. A administração de Nassau foi um marco importante tanto para a efetivação dos holandeses no Brasil quanto para difundir a cultura holandesa no país.

Nassau ficou conhecido pelos muitos trabalhos realizados para desenvolver a colônia. Ele vendia engenhos que haviam sido abandonados durante a guerra entre Portugal e Holanda como forma de tentar recuperar a atividade açucareira de Pernambuco. O administrador ainda estabeleceu algumas regras com intuito de melhorar a vida dos holandeses como por exemplo a obrigatoriedade do plantio de mandioca, proibição de jogar lixo nas ruas, entre outras medidas que visavam o bem-estar da sociedade em geral.

No período em que esteve à frente da colônia Maurício Nassau estimulou as ciências e as artes. Dentre as contribuições temos: construção de um observatório astronômico, criação de um jardim botânico e direção de um projeto chamado "exploração profunda e universal da terra" onde trouxe consigo em sua comitiva mestres da pintura flamenga como Albert Eckout e Franz Post além de outros artistas e cientistas convidados

As principais influências deixadas pelos holandeses advindas do processo de colonização foram na literatura de cordel, nas blasfêmias no folclore do açúcar e em elementos de confeitaria e laticínios. Além disso também fizeram melhoramentos urbanísticos, produção de uma arquitetura não religiosa, de pinturas e desenhos documentando a paisagem, urbana e rural, retratos, figuras humanas e de animais, naturezas-mortas e difusão de métodos racionais de cultura agrária, através da adubação, fertilização e aplicação de rotação de culturas. 
Acerca da colonização holandesa no Brasil Mello (2001) afirmou que os holandeses vieram em busca da hegemonia econômica, política, religiosa e cultural e que não conquistaram de maneira pacífica. Houve resistência por parte dos ibéricos, indígenas, negros e judeus. No entanto, lutaram pela supremacia do poder e, mesmo em meio às lutas, pode-se vislumbrar a importância desse período em que a colônia brasileira foi ocupada pelos flamengos: sua arquitetura, os sobrados estreitos, o uso dos tijolos holandeses, os hábitos alimentares, suas relações com a colônia e a metrópole, as plantações de cana e os engenhos de açúcar, a religião calvinista, o catolicismo, o clero e as outras ordens religiosas estabelecidas. O contato diário era propício pra um estreitamento entre as diversidades culturais, porém não se pode negligenciar o fato de que a hierarquia econômica foi determinante para o encadeamento das relações sociais pautadas pela reprodução do capital.

A decadência da colônia holandesa ocorreu a partir do ano de 1640 e foi assinada a carta de rendição no ano de i654. Os problemas econômicos enfrentados pela Companhia Holandesa das Índias Ocidentais foi um dos principais fatores que fez com que com que a WIC não investisse o necessário para garantir a segurança de sua colônia.

\section{METODOLOGIA}

A metodologia utilizada para a elaboração deste trabalho foi a de pesquisa bibliográfica, exploratória e descritiva, tendo como referências literaturas sobre o assunto, consulta em artigos de internet na área da história do Brasil, colonização e diversidade cultural com o objetivo de induzir o leitor a refletir e questionar sobre a ligação da cultura atual com a história do país.

Segundo Lakatos e Marconi (1987) a pesquisa bibliográfica trata-se do levantamento, seleção e documentação de toda bibliografia já publicada sobre o assunto que foi pesquisado em livros, enciclopédias, revistas, jornais, folhetos, boletins, monografias, teses, dissertações e material cartográfico. Lima em seu estudo sobre "A importância de trabalhar o ensino da história e da cultura afro-brasileira e africana em sala de aula" definiu a pesquisa bibliográfica como: 
A pesquisa bibliográfica é o primeiro passo para se realizar uma investigação, pois a pesquisa bibliográfica abrange a pesquisa através da leitura, análise $e$ interpretação de livros, periódicos (jornais, revistas etc.), artigos, documentos monográficos, sites confiáveis, entre outros documentos que são as fontes secundárias mais utilizadas para esse processo." (LIMA, 20I6, p.2I).

Para o alcance do objetivo proposto acima foi utilizada a metodologia de pesquisa qualitativa. Entendemos pesquisa qualitativa como uma metodologia que abrange estudos que "podem descrever a complexidade de determinado problema, analisar a interação de certas variáveis, compreender e classificar processos dinâmicos vividos por grupos sociais” (RICHARDSON, i999, p. 80).

Partindo dos conceitos apresentados por historiadores, estudantes e pesquisadores da história do Brasil e relações entre colonizador e colonizado, o trabalho enumerou as diversas influências que formaram a cultura brasileira. Cultura essa que teve sua identidade construída em decorrência do passado histórico do país. A cultura brasileira não possui uma identidade autêntica, mas uma pluralidade de identidades, construídas por diferentes grupos sociais e em diferentes momentos históricos.

\section{CONSIDERAÇÕES FINAIS}

O presente trabalho enumerou as diversas influências que a cultura brasileira sofreu ao longo dos anos devido ao processo de colonização. Muitos foram os povos que vieram para o Brasil, alguns voluntariamente buscando expandir seus mercados em buscas de riquezas outros sem o poder de escolha como um objeto destinado ao trabalho compulsório. Os portugueses foram os primeiros colonizadores a chegarem no território brasileiro e conseguiram por vários anos ter o monopólio da região. Inicialmente utilizaram os índios nativos que viviam por aqui para os trabalhos com a terra. Posteriormente trouxeram para o Brasil africanos que além de mão-de-obra para o trabalho ajudavam a movimentar o comércio de escravos. Os lusitanos obrigavam os escravizados a seguirem seus costumes e crenças, porém foi inevitável a propagação da cultura destes em todo o país. A principal influência que Portugal deixou aos brasileiros foi a língua portuguesa que é a oficial do Brasil. O catolicismo, religião majoritária atual, foi a religião oficial do Estado até a Constituição Republicana de I89ı, que instituiu o Estado laico. Diversas festas típicas e de tradições como carnaval e festas juninas que existem no século XXI também foram 
herança dos portugueses. Os franceses, importantes influenciadores e presentes no Brasil colônia, foram os responsáveis por difundir sua arte, estilo de vida e a intelectualidade. Os holandeses deixaram marcas na literatura, folclore, urbanismo, fertilização e produção de uma arquitetura que fugia dos padrões. Já os índios e africanos apesar da tentativa de extermínio por parte dos colonizadores de suas identidades culturais disseminaram a cultura de seu povo por diversos estados brasileiros. Esse misto de etnias, costumes, crenças e ideias que transitaram pelo Brasil desde os tempos da colônia foram os responsáveis pela construção da diversidade cultural que se iniciou na época da colonização e se estendeu na história até os dias de hoje. A cultura brasileira está propriamente ligada a história do Brasil reafirmando assim a tese defendida por Antônio Gramsci quando disse: “todo indivíduo é não somente a síntese das relações existentes, mas também da história destas relações, isto é, o resumo de todo o passado" (GRAMSCI, I995, p. 40).

\section{REFERÊNCIAS}

FAUSTO, Boris. História do Brasil: História do Brasil cobre um período de mais de quinhentos anos, desde as raízes da colonização portuguesa até nossos dias. São Paulo. Editora da Universidade de São Paulo, 1996.

GRAMSCI, Antonio. Concepção Dialética da História. Rio de Janeiro: Civilização Brasileira - ı. ed., 1995.

LIMA, Macedo Karoline Hanna de. A importância de trabalhar o ensino da história e da cultura afro-brasileira e africana em sala de aula. Paraíba, 2016.

LAKATOS, Eva Marina; MARCONI, Marina de Andrade. Metodologia do Trabalho Científico. 2. ed. São Paulo: Atlas, 1987.

SOUSA. Mari Guimarães. Re-visitando a história: colonização portuguesa e subordinação cultural. Bahia: FACOM-UFBA, 2008.

MELLO, José Antônio Gonçalves. Tempo dos Flamengos. Rio de Janeiro: Topbooks, 200 .

NETTO, B. A.; DIAS, P. E.; MELLO, R. C.P. Análise da obra cultura organizacional e cultura brasileira organizada por Fernando C. Prestes Motta e Miguel P. Caldas. 2. ed.Vol.2. São Paulo. Revista eletrônica de administração - FACEF, 2003. 


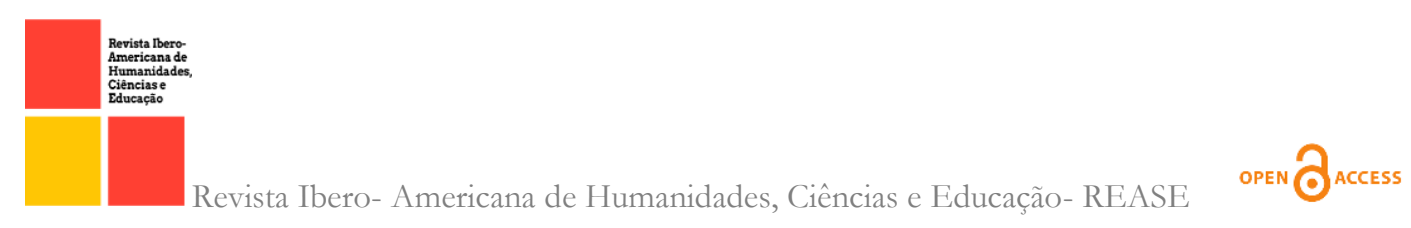

PETER, Glenda Dimuro. Influência francesa no patrimônio cultural e na construção da identidade brasileira: o caso de Pelotas. Disponível em: < http://www.vitruvius.com.br/arquitextos/arqooo/esp429.asp > Acesso em 25 de março de 2020.

PRADO JR., Caio. Formação do Brasil contemporâneo: colônia. São Paulo: Brasiliense; Publifolha, 2000 ( $\mathrm{I}^{\mathrm{a}}$ edição: 1942 ).

RIBEIRO, Gonçalves Maria Rita. A Europa na identidade nacional. Portugal. Universidade do Minho, 2008.

RICHARDSON, Roberto Jarry. Pesquisa social: métodos e técnicas. 3. ed. São Paulo: Atlas, 1999.

SILVA, Ana Cristina N. da e HESPANHA, Antônio M. A Identidade Portuguesa. In: HESPANHA, Antônio M. (Org.). História de Portugal Vol. 4. Lisboa: Estampa, 1993.

SILVA, Carmelindo Rodrigues. A experiência portuguesa no processo de colonização do Brasil. In: LOMBARDI, José Claudinei; SALVIANI, Dermeval e NASCIMENTO, Maria Isabel Moura (orgs.). Navegando pela história da educação brasileira. Campinas: São Paulo. FE: HISTEDRH, 2006. 